\title{
Historical review of arthroscopic surgery of the hip
}

\author{
Abigail C.L. Magrill ${ }^{1} \cdot$ Naoki Nakano $^{2} \cdot$ Vikas Khanduja $^{2}$ (D)
}

Received: 6 December 2016 / Accepted: 16 March 2017 / Published online: 9 May 2017

(C) The Author(s) 2017. This article is an open access publication

\begin{abstract}
Background \& purpose Increasing our appreciation of the historical foundations of hip arthroscopy offers greater insight and understanding of the field's current and future applications. This article offers a broad history of the progress of hip arthroscopy. Methods Hip arthroscopy's development from the early technologies of endoscopy to the present day is described through a review of the available literature.

Results Endoscopic science begins with the Lichtleiter, developed by Phillip Bozzini (1779-1809) in 1806, but endoscopes were not applied to joints until 1912, as presented by Severin Nordentoft (1866-1922). The work of Kenji Takagi (18881963), especially, was instrumental in the arthroscope's development, allowing Michael Burman (1901-75) to perform the first recorded hip arthroscopy, detailed in a 1931 paper after extensive cadaveric research. Although World War II stalled further development, a renewed application of fibre optics following post-war innovations in glass manufacture heralded the modern arthroscope's invention. During the 1970s hip arthroscopy was first mobilized for diagnosis and exploration, leading to its later adoption for therapeutic surgical interventions. Modern hip arthroscopy has been facilitated by international research into optimum distraction, portals of entry, positioning of patients, and the technology of arthroscopic instruments. In
\end{abstract}

Abigail C.L. Magrill and Naoki Nakno are co-first authors which means they contributed equally to this work.

Vikas Khanduja

vk279@cam.ac.uk

1 University of Cambridge School of Clinical Medicine, Box 111, Cambridge Biomedical Campus, Cambridge CB2 0SP, UK

2 Department of Trauma and Orthopaedics, Addenbrooke's Hospital, Cambridge University Hospitals NHS Foundation Trust, Box 37, Hills Road, Cambridge CB2 0QQ, UK
2008, the International Society for Hip Arthroscopy (ISHA) was founded to represent this international expert community. Conclusions Technology, communication and evidencebased medicine have jointly facilitated the development of this young but promising corner of Orthopaedics.

Keywords History of orthopaedics · Hip arthroscopy · Endoscopy $\cdot$ Historical review

\section{Preface: early arthroscopy — from bladder to the joint}

Hip arthroscopy is often thought of as a relatively new procedure. Certainly its clinical indications and use have seen a huge rise in popularity, and a corresponding explosion in literature, over the last two decades. However, an arthroscope was first inserted into a hip joint in 1931, and some hundred years before that of the development of endoscopy and arthroscopy laid the foundations on which this could happen. Endoscopic efforts, in general, began in earnest with Philipp Bozzini, a young German army surgeon who was frustrated by trying to locate bullets in his patients [1]. In 1806 he developed the Lichtleiter - a short, clumsy instrument that nonetheless is the ancestor of all modern endoscopes. It used two tubes and a candle to visualise the inside of the bladder [2] (Fig. 1). It paved the way for further exploration and invention, as the instruments for observing the bladder were improved and aided with trans-illumination. This marked the birth of endoscopy as a surgical science.

It was more than a hundred years before the cystoscope was turned to the joints. The first instance of arthroscopy is often attributed to the Japanese professor Kenji Takagi, but the previously ignored proceedings of the $41^{\text {st }}$ Congress of the German Society of Surgeons in 1912 [3], rediscovered in 

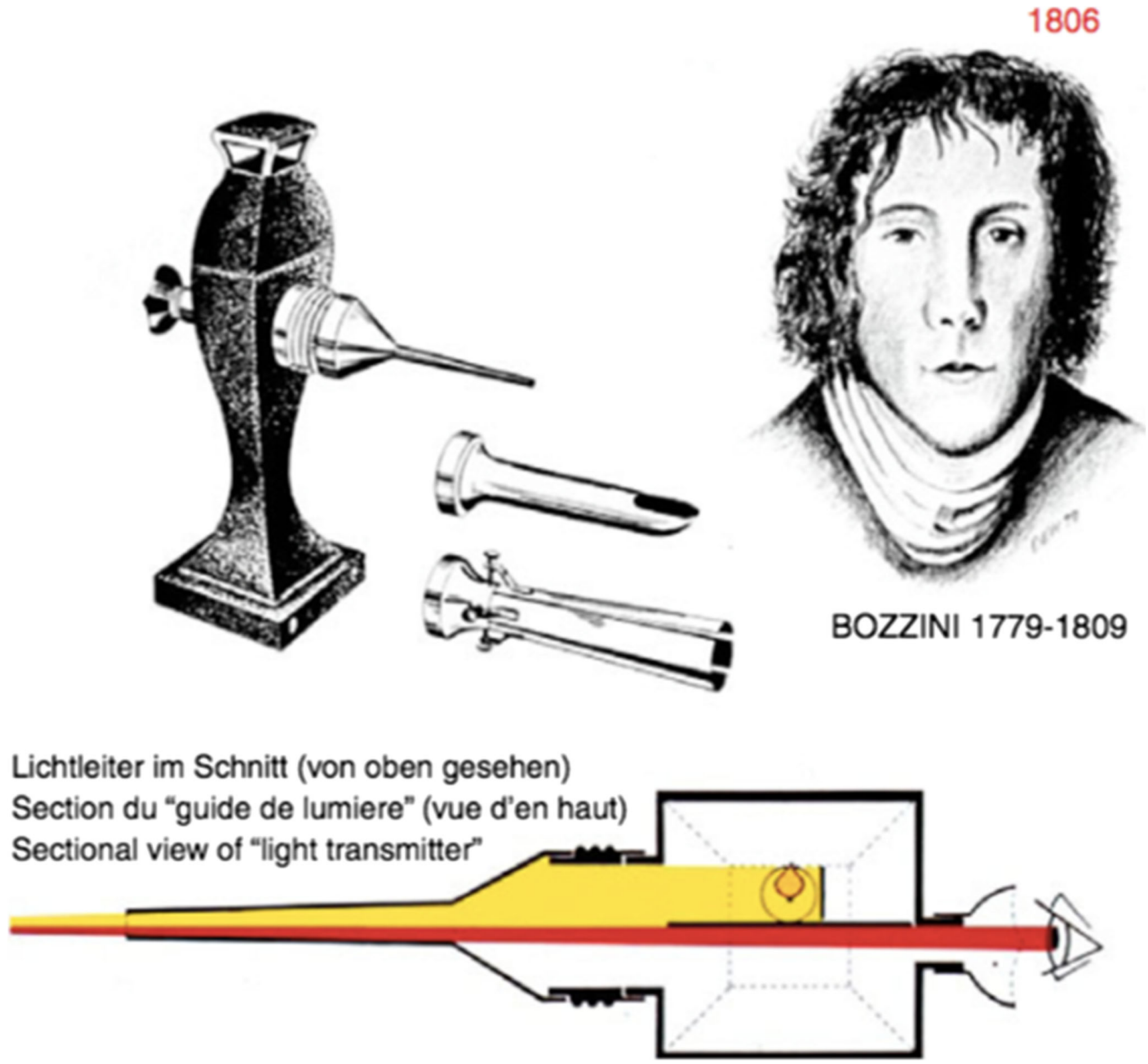

Fig. 1 Passler and Yang 2012 - section 'the past and the future of arthroscopy' in book 'Sports Injuries: Prevention, Diagnosis, Treatment and Rehabilitation' ISBN 978-3-642-15629-8

2001 [4], reveal that Severin Nordentoft, a Danish surgeon from Aarhus, presented his findings from arthroscopy of the knee using a Trockard Endoscope. Nordentoft even used the term 'arthroscopy' and gave a vivid account of his exploration of the knee, but his pioneering work was largely overlooked. More famously and influentially, Takagi first used a cystoscope to examine cadaver knee joints in 1918. The cystoscope of his day was quite different from Bozzini's candle-and-tube creation but it was nonetheless some years before he could decrease its $7.3 \mathrm{~mm}$ diameter to a more convenient size for entering a joint. He developed his No. 1 arthroscope in 1931, which was a $3.5 \mathrm{~mm}$ diameter instrument much more convenient for accessing a knee (Fig. 2). He also developed a number of other arthroscopes and instruments for performing basic and simple surgery in the knee, such as intra-articular biopsy. Takagi wanted to wait until he had perfected these techniques before he presented on the subject in 1933 to the Japanese Orthopaedic Association [5], and so parallel developments were made in the west. Eugen Bircher, in Switzerland, described the use of a Jacobeus Laparoscope in the knee joint in 1921 [6], but found limitations in his equipment frustrating enough to abandon his arthroscopic efforts, as he described at the meeting of the German Surgical Society in 1933 [7]. By this time, though, he noted the developments of the American arthroscopy pioneer Michael Burman and hoped his efforts might be successful. 


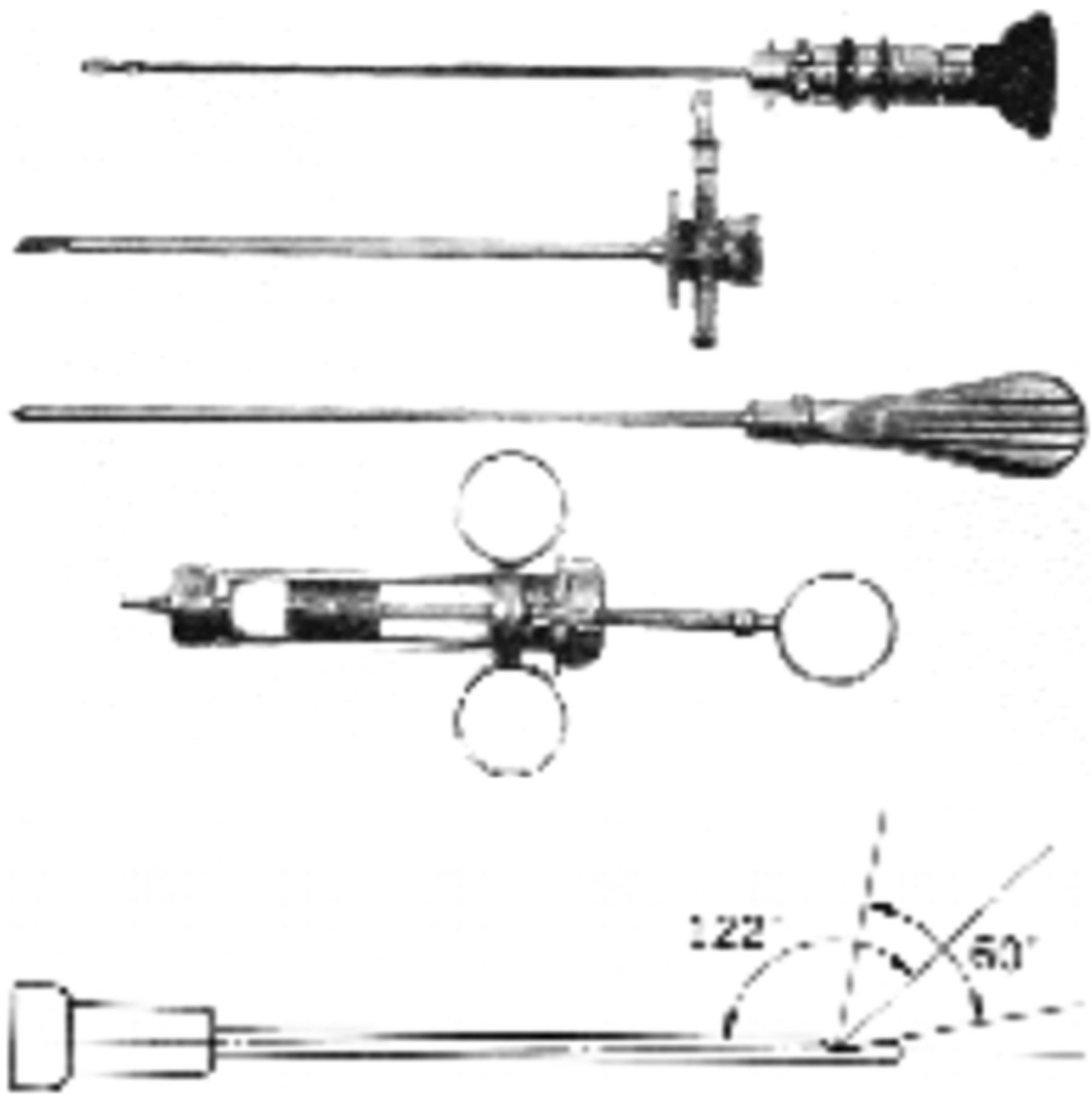

Fig. 2 From Passler and Yang 2012 (see above)

\section{Early efforts in the hip — before 1970s}

Burman published a comprehensive article on arthroscopy in 1931, that detailed his many experiments on cadaver joints, including the hip joint [8] (Fig. 3). This is the first time hip arthroscopy was mentioned in the literature. Burman attempted to examine knee, hip, shoulder, wrist, ankle and elbow joints. He found the shoulder amenable to visualisation; the knee and wrist presented initial difficulties, which he was able to overcome as he developed his techniques; he found the ankle and the elbow unsuitable for arthroscopy; and the hip he was only able to visualise partially. He described: 'One cannot hope to see the acetabular fossa with its outlying horseshoeshaped fibrocartilage (the so-called facies lunata), the incisura acetabuli, the ligamentum teres, or the part of the head of the femur about the fovea capitis femoris that is always in the joint, even in the rotation. Neither can the space between the head of the femur and the upper acetabular rim be seen since it is covered by fat and capsule' [8].

However, he was able to visualise the intra-capsular part of the neck of the femur, and some of the head of the femur the peripheral compartment of modern hip arthroscopy. By placing 

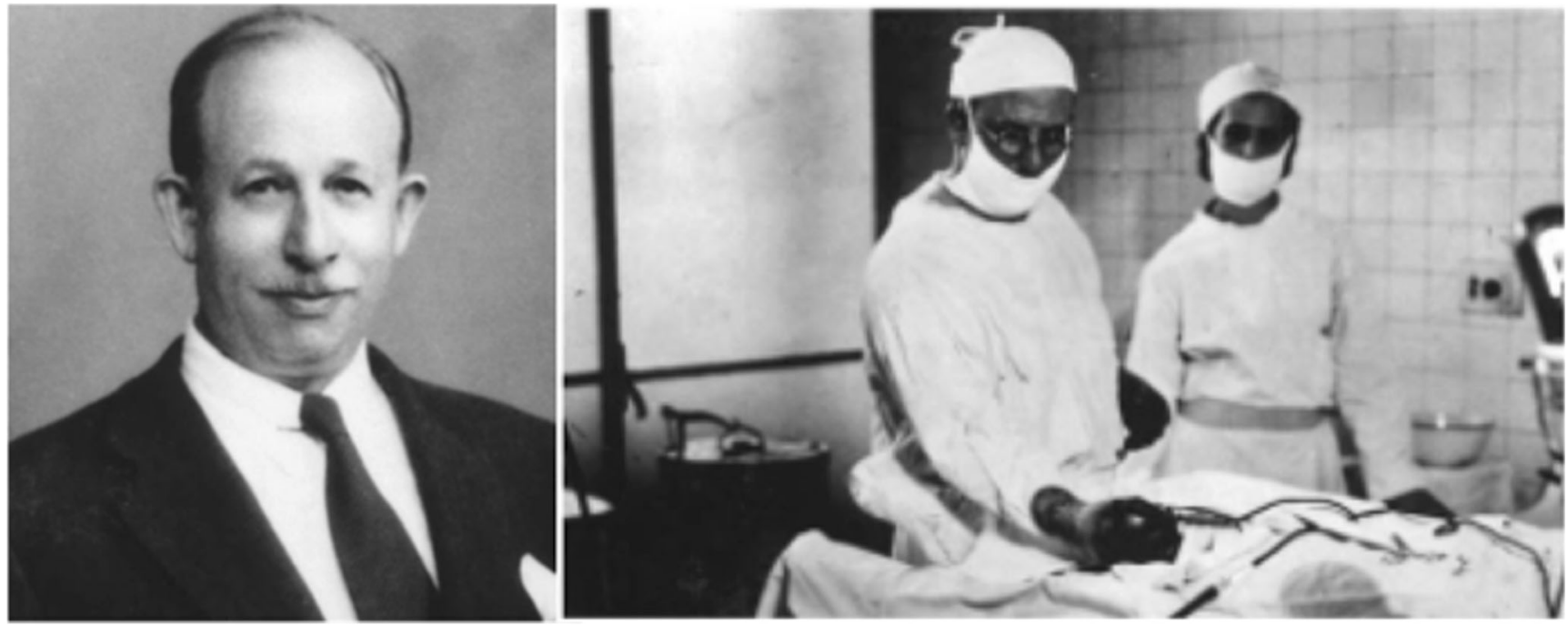

Fig. 3 Byrd 2013 - Springer 'Overview and History of Hip Arthroscopy’ in book 'Operative Hip Arthroscopy’ ISBN 978-1-4419-7924-7

the hip through the range of motion, he could see much of the articular surface of the femoral head even without distraction.
His observations, comments and beautiful illustrations (Fig. 4) are still of relevance and importance today. For access, he
Amritiosecor

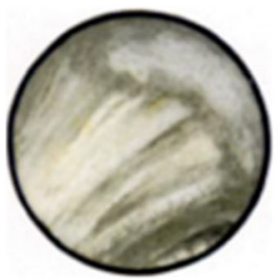

A
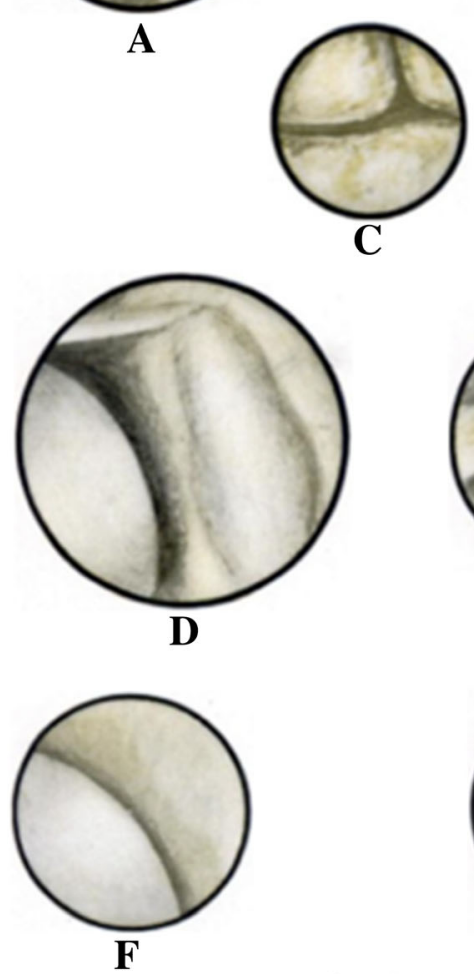

$1 \mathrm{~km}$
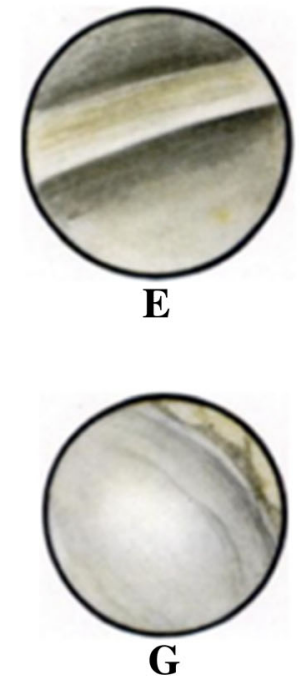

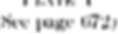

673

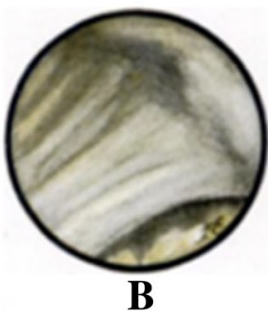

PLate I

$A$ and $B$. Views of two different hip joints of adults. Anterior paratrochanteric puneture used. Hip in external rotation, slight abduction, and neutral to flexion or extension. In both these cases, only a small part of the joint space is seen, with fat projecting into it. The neck of the fermur with its ridgings, the junction between bead and neck, and a part of the besd are seet. More of the superior and upper surface of the Deck is shown.

C. A view of the wriat joint through the usual doral puncture. The lower end of the radiug, a large part of the scaphoid, and s amall part of the semilunar bone sre seeo. Note particularly the interearpal joint between the acaphoid and secoilunar bones, com. municating with the main wriat joint cavity.

D. View of the shoulder joint of a child through the umual anterior puncture. Note the besd of the humerus, the glenoid fosan with its outlying ring or labrum of fbrocartilage. The origin and courne of the long head of the bicepa should be noted.

E. Shoulder joint of an sdult through the anterior puneture. Views $E, F, G$ are all taken from the same case. The long bead of the biceps is seen as it courses through the darkiah joint cavity.

$F$. A part of the head of the humerus. cated.

G. A view of the glenoid fosan. The origis of the tendon of the bictep is not indi-

Fig. 4 Burman 1931 'Arthroscopy or the direct visualization of joints' in The Journal of Bone and Joint Surgery 13(4):669-94 
advocated the anterior paratrochanteric puncture, slightly anterior to the greater trochanter and along the course of the neck of the femur. This is still the major working portal for much modern hip arthroscopy. He also suggested that the positions of the femoral artery and head of the femur be marked beforehand so that damage to the vessels 'should be only a theoretical accident'. He reported that it was 'manifestly impossible to insert a needle between the head of the femur and the acetabulum'. This difficulty in access remains applicable. Although extracapsular work is now done, for instance, release of a snapping iliopsoas tendon, distraction remains necessary to visualise the central compartment, a luxury that Burman did not have.

Takagi continued to work on arthroscopy and published a paper reporting the first clinical application of hip arthroscopy in 1939: to treat Charcot's joints, tuberculous arthritis and infectious arthritis in four patients [5]. Although World War II halted any research or progression in this field, Masaki Watanabe, a protégé of Takagi's, continued to develop much more sophisticated endoscopes using electronics and optics (Fig. 5), which became popular in the post-World War II era in both Japan and America. His Atlas of Arthroscopy [9], first published in English in 1957 and the particularly influential second edition in 1969, engendered a widespread interest in clinical applications of arthroscopy, particularly of the knee. Despite this growth of arthroscopy in general, clinical applications of arthroscopy of the hip were largely ignored from Takagi's paper of 1939 until the 1970s.

\section{Developments in the 1970s and early 1980s}

The International Arthroscopy Association was founded in 1974, and Watanabe elected as its first president. At its first meeting in Copenhagen, in 1975, a French surgeon Aignan opened a new chapter in hip arthroscopy with his presentation of attempted diagnostic arthroscopy and biopsy of 52 hips [10]. This presentation was closely followed by the publication of two paediatric clinical series: the first by Richard Gross, based in the United States, in 1977 [11], and the second by Svante Holgersson et al, a Swedish team, in 1981 [12]. Gross described the diagnostic applications of hip arthroscopy in 27 patients with a variety of paediatric hip disorders. He used a $2.2 \mathrm{~mm}$ arthroscope with an anterior portal and a subadductor portal. The manual distraction of the joint by pulling

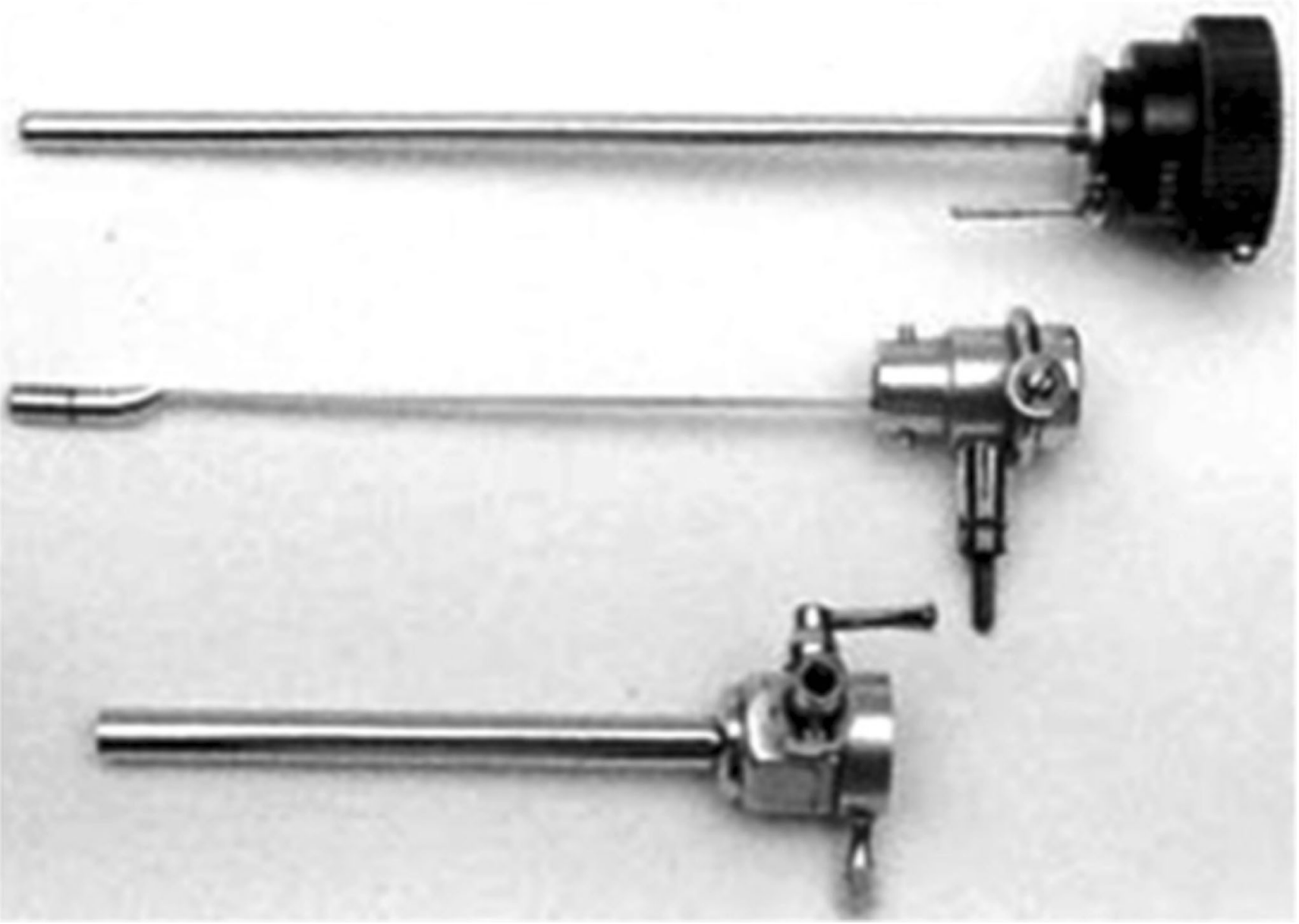

Fig. 5 From Passler and Yang 2012 (see above) 
on the foot was 'occasionally helpful in facilitating entry of the arthroscope' into the joint space, but not used throughout the procedure. The lateral compartment was still the focus of the arthroscopy. He used arthroscopy to visualise disorders including developmental dysplasia of the hip, Legg-CalvePerthes disease, neuropathic subluxation, prior sepsis and slipped capital femoral epiphysis. He noted that in a few of the patients with chondrolysis, there was a reported decrease in pain after the arthroscopy, presumably due to mechanical lavage, and foresaw that hip arthroscopy might have successful therapeutic as well as diagnostic applications. The photography in his report was, as he noted in private correspondence with ACLM, 'very primitive. I held an SLR camera against the eyepiece and guessed at the exposure', and 'did not know whether I had anything worthwhile until the slides were developed' (Fig. 6). This is quite remarkable when compared with the fibre-optic, live video guidance used by today's hip arthroscopists. Meanwhile, the Swedish team, led by Holgersson, used traction and distension with physiological saline to visualise 15 hips in patients suffering from juvenile chronic arthritis. They concluded that arthroscopy gave good information about the synovial membrane and the cartilage compared to existing techniques, and should be performed early in the course of hip disability.

Two case reports were published in 1980 describing the removal of entrapped cement fragments after total hip replacement using arthroscopy, one from New York [13] and one from Israel [14]. The geographical disparity of these important

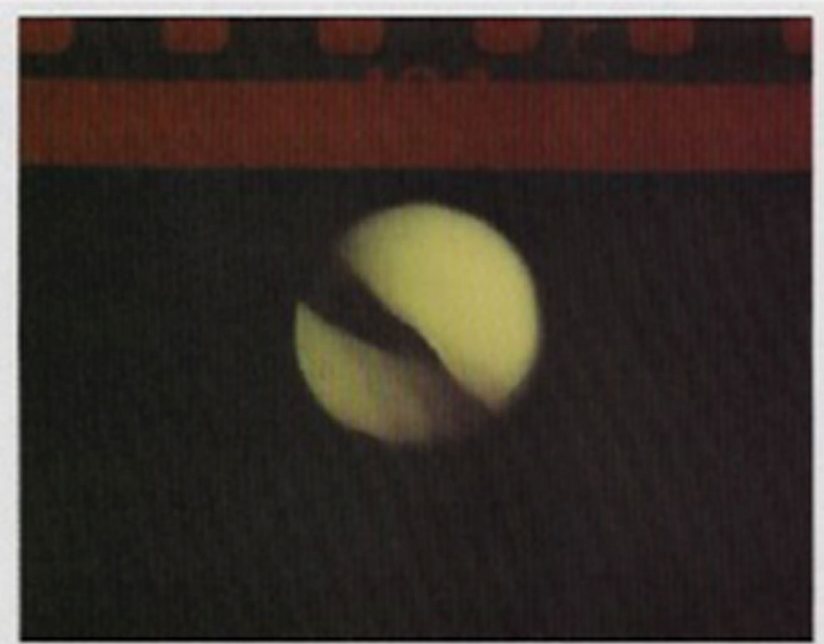

Fig 4. Various spabal relationships demonstrated by manipulation of the log can be seen at arthroscopy of the same patient shown in Figures 7,2 and 2 In this view the femoral head overlaps the carvaginous isbrum.

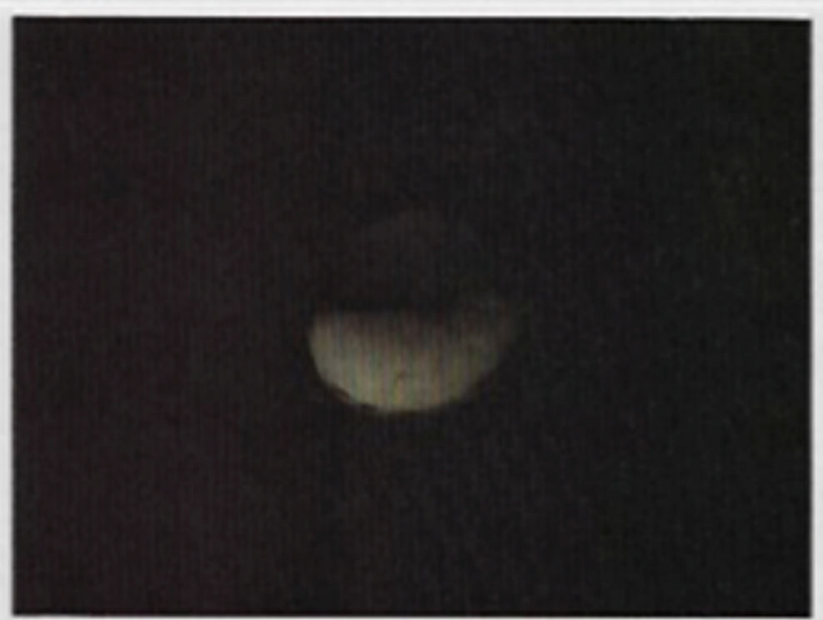

Fig 8. This arthroscopic viow of the same patient in Figures 6 and 7 shows the medial femoral head to be smooth, with an abrupt change in the charecter of the articular carnilage as the leteral head is visualied.

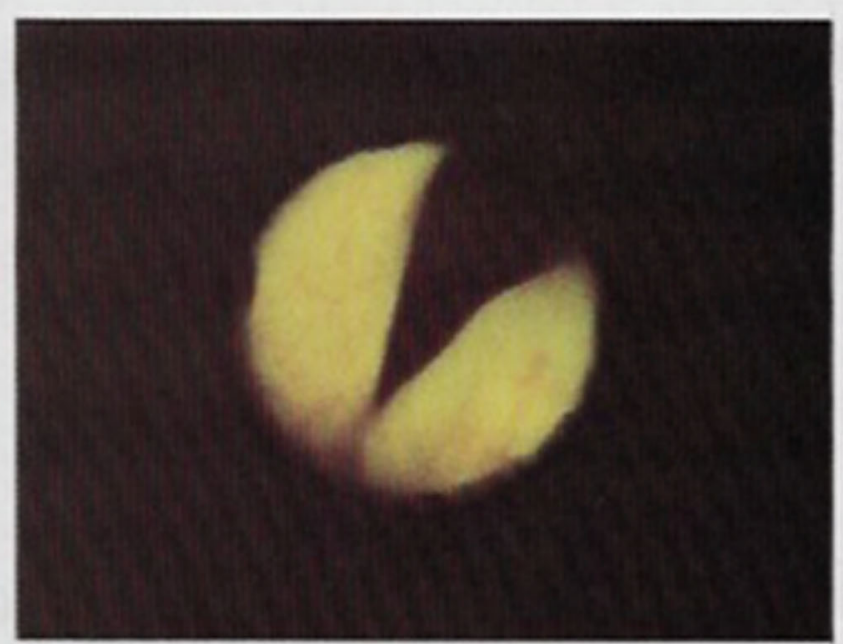

Fig 5. The seme patient shown in Figures $f$ to 4. in this arthroscopic view, the linear structure at the left is figamentum fores with a dolicate vascular network. The somowhat flattoned femoral head is at 5 o'clock the perichondrial vasculer ning is easily identifed.

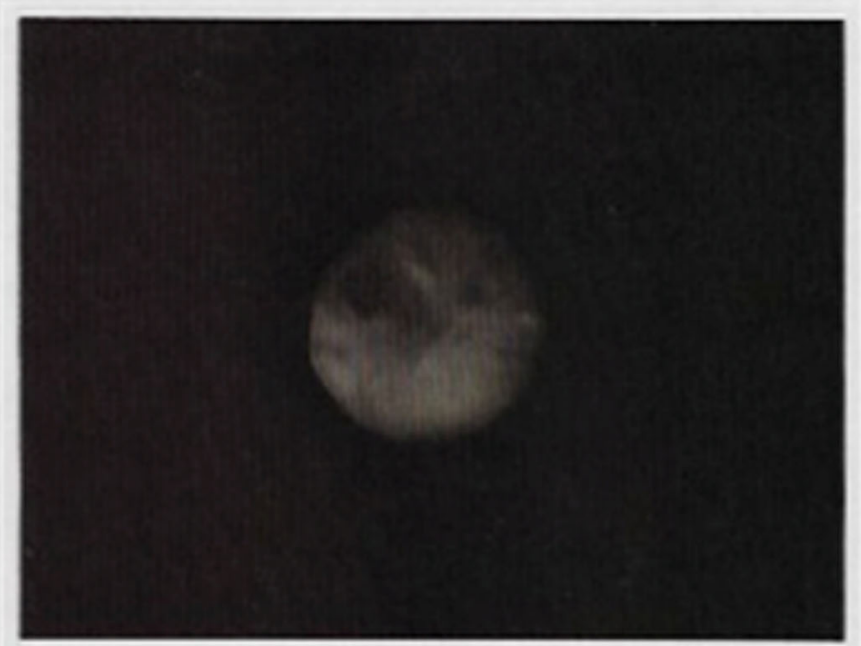

Fig 9, in this arthroscopic view of the patient in Figures 6,7 and 8 , the lateral Np of the acetabulum is seen in the Deckground with severe fibrillation of the femoral head at this level.

Fig. 6 Richard Gross, 1977 'Arthroscopy in Hip Disorders in Children'. Orthopedic Review 6:43-49 
publications goes to show the beginning of an international era of communication. Thus, technology plays a key role in this history not just through the quest for more and more efficient arthroscopes, but through the developing communication and sharing of information that occurred as this new surgical science came of age in an increasingly technological era. In the 1980s, techniques were developed to enhance hip arthroscopy's diagnostic value as well. Eriksson et al worked on the distraction of the hip in both anaesthetised and nonanaesthetised patients [15], concluding that less force was needed in anaesthetised patients. This latter group of awake volunteers included, somewhat heroically, Eriksson himself. They documented the forces necessary for good arthroscopic viewing of the anterior compartment: $300-500 \mathrm{~N}$ in anaesthetised patients or $900 \mathrm{~N}$ in non-anaesthetised patients through an anterior portal. This development of distraction was to allow future surgeons to access and operate on the important structures of the central compartment: the labrum, articular cartilage, and ligamentum teres.

The development of arthroscopy, in general, had led to the availability of better arthroscopes for use in the knee and shoulder, and in the 1970s these were most commonly employed in early hip procedures [16]. These arthroscopes, however, were still optical structures through which the surgeon could look down the eyepiece and, using a contraption of mirrors and yellow light, have a rudimentary view of structures in the joint. It is evident from annotated pictures in, for instance, Gross's 1977 publication that the identification of structures and pathologies required great skill and experience with these arthroscopes, and that accurate photography of these views for teaching and research was very difficult and frequently frustrating [11].

In the late 1970 s and early 1980 s, a few key surgeons published extensively and pushed the field forwards. James Glick in San Francisco began performing hip arthroscopy in 1977, and along with his partner Thomas Sampson, he developed the new technique of putting the patient in the lateral decubitus position (Fig. 7) . They published their preliminary findings in 1987 [17] and continued to publish on the subject in journals and books. Glick reported that they had difficulty accessing and visualising the joint in more than $40 \%$ of patients in the supine position on a fracture table, particularly in

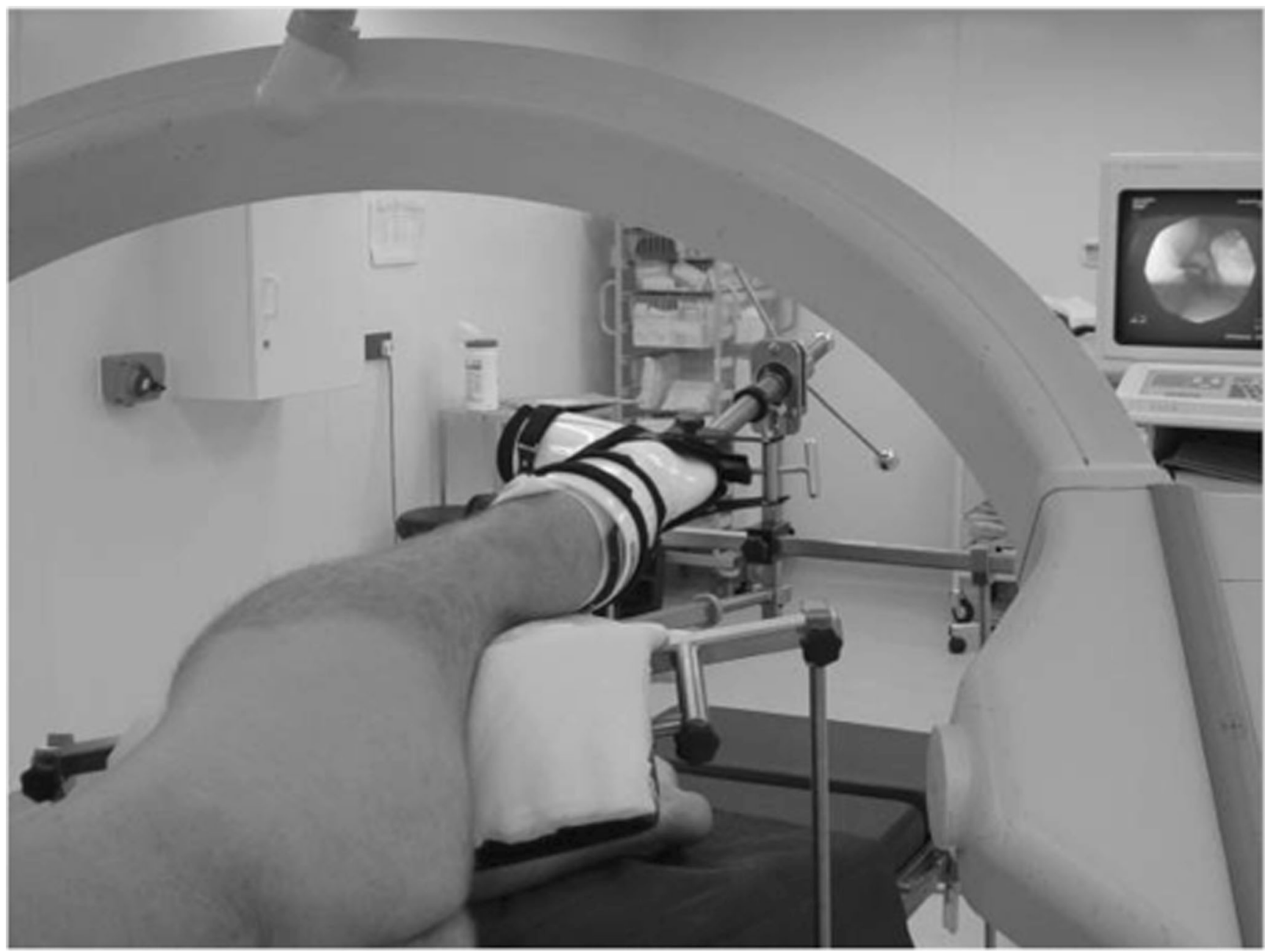

Fig. 7 Villar R \& Shetty V 2007 'Hip arthroscopy: current concepts and review of literature' in British Journal of Sports Medicine 41(2):64-68 
those patients who were overweight and obese [17]. They were also worried about the safety of the supine position, with many intra- and extra- articular structures vulnerable in the placement of portals. This led them to attempt to visualise the joint with a different patient position, and they found this lateral decubitus position much more effective. As well as this influential lateral position, Glick and Sampson discussed the relevant anatomy, portal placement and indications for hip arthroscopy, thereby equipping their readers with a thorough basis for consideration of the technique.

The relatively short length of an arthroscope meant that the early lens-based models such as Wantabe's (which had an offset light bulb and an arthroscopic valve) were adequate for early hip arthroscopy experimentation, but another huge leap was made when fibre-optic technology was introduced to arthroscopy. Scientific research on the properties of light that make it applicable to fibre-optic technology has a long history, but this was not applied to medical endoscopy until relatively recently. It was known as early as 1870 that light could be conducted along a curved path of water [18], and this was applied to a technique for transmitting light through flexible quartz or glass fibre bundles in 1928 [19]. However, these experiments did not immediately lead to useful applications, and although fibre-optic technology in telecommunications was advanced, its applications to endoscopy were not realised until the 1950s when research began to emerge on the possibility of transmitting images along an aligned bundle of flexible glass fibres. Post-war glass manufacturing enjoyed a major improvement that meant that the light loss in transmission through the glass was greatly reduced. This made it possible for the breakthrough of 1954, when papers by A.C.S. van Heel in Holland and H.H. Hopkins and his student, N.S. Kapany, in the department of physics at the Imperial College in London, were simultaneously published in Nature [20, 21]. These papers reported the principles of conveying a coherent optical image along a glass fibre. Hopkins and Kapany were the first to present the principles of fibre alignment. A young South African gastroenterologist, Basil Hirschowitz, who was on a fellowship in Michigan, read these papers [22] and saw that the clumsy endoscope on which he had been taught could benefit from this technology. He visited Hopkins and Kapany in London in the summer of 1954 and found that their equipment was far from any clinical use but the technology was promising. Hirschowitz and his student Larry Curtiss back in Michigan were able to develop the technology to make fibre optics applicable to endoscopy, and Hirschowitz first used it on himself in February of 1957. "I looked at this rather thick, forbidding but flexible rod, took the instrument and my courage in both hands, and swallowed it over the protests of my anaesthetised pharynx and my vomiting centre" [22]. A few days later he used it to examine a patient suffering from a duodenal ulcer Hirschowitz and Curtiss eventually worked with manufacturers to produce adequate optical fibres and by the mid1960s 'gastrocameras' were widely used.

Fibre optic endoscopes took their time to be applied to arthroscopy since the optical arthroscopes could provide better image quality over a short length. They have now been superseded by the invention of the charged coupled device in the 1960s, which allows the creation of a digital electronic image, permitting endoscopic images to be processed by a computer and displayed on television screens [23]. This now means that the arthroscopic view can be recorded and stills can be captured for information sharing and education purposes. The image quality is excellent so that the surgeon can visualise the joint and the intervention clearly.

In the United Kingdom, in the mid-1980s, Richard Villar from Cambridge corresponded with both James Glick and Richard Hawkins (another of the few who had, at this point, published on the subject [24]), and began to pioneer hip arthroscopy on the British side of the Atlantic. He went on to become the founding member and first president of the International Society for Hip Arthroscopy (ISHA). His 1992 textbook [25] was the first available specifically on the subject, and together with his enthusiastic advocacy and teaching skills helped to inspire a generation of hip arthroscopists including the senior author and the widespread use of conservative hip surgery in the UK. He continues to practice, teach, and publish on the technique, as do many of these pioneers who are still active today: James Glick and Thomas Sampson in San Francisco,Joseph McCarthy in Boston, Thomas Byrd in Nashville and Richard Gross, who kindly shared his 1977 paper with us. This 'history' is one that is recent enough to have characters within reach, which only makes it more engaging. These new techniques and few enthusiastic first players collaborated across continents to raise the profile of hip arthroscopy, and by the early 1990s, the stage was set for widespread uptake and furthering of the field.

\section{Widespread uptake and prolific expansion of the literature from the $1990 \mathrm{~s}$}

Villar's paper of 2007, along with Vijay Shetty, reported the current state of hip arthroscopy as a promising technique but one that was still not widely available due to its requirements for special equipment and difficult surgical skills [26]. However by the late 1980s and early 1990s, this was beginning to change with numerous publications emerging. As hip arthroscopy became more popular, medical equipment companies began to develop specific arthroscopes and technology, including longer arthroscopes and telescoping cannulas [16].

J.W. Thomas Byrd who is based in the United States began publishing around this time and made an elegant case for ways in which the supine position (Fig. 8) could be modified to 


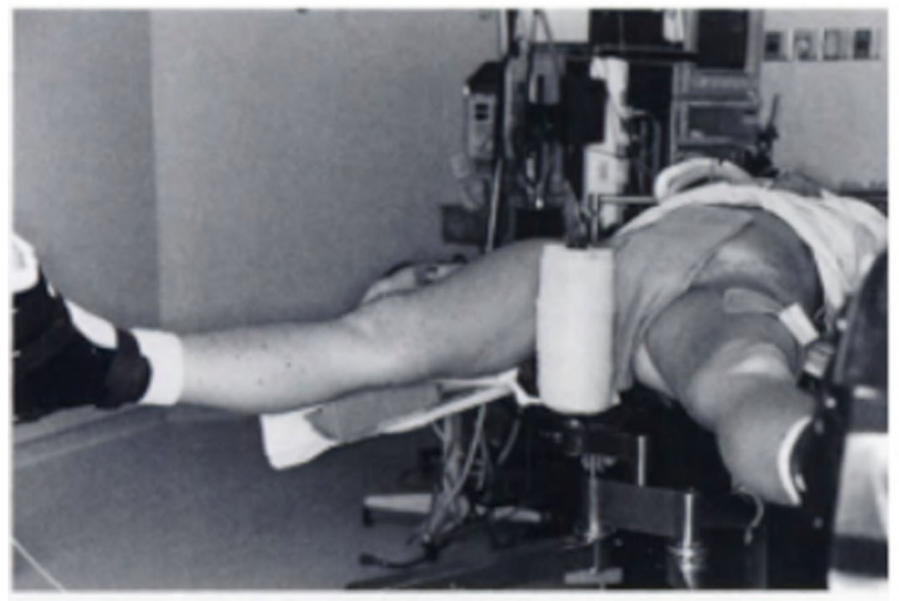

FIGURE 27.10. The patient is positioned on the fracture table so that the perineal post is placed as far laterally as possible toward the operative hip resting against the medial thigh. (From ref. 13, with permission.)

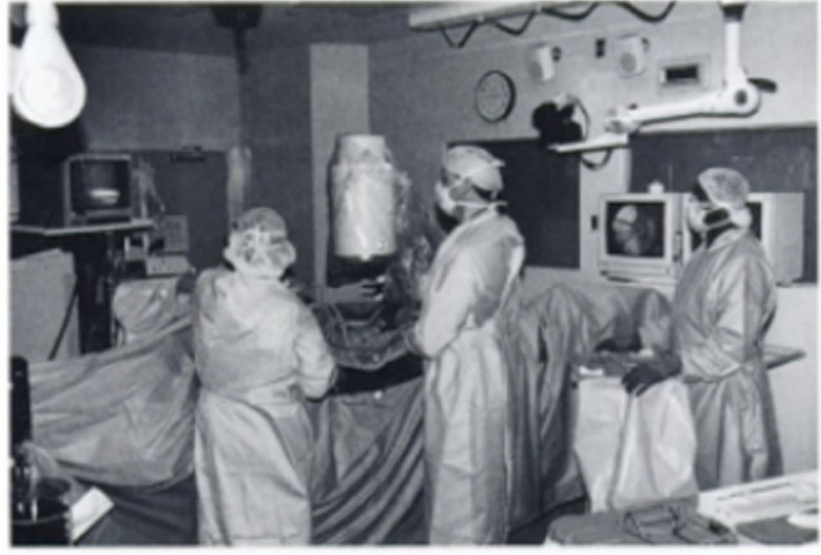

FIGURE 27.12. The surgeon, assistant, and scrub nurse are positioned on the operative side. The arthroscopy cart with monitor is on the nonoperative side. The C-arm, covered in a sterile drape, is positioned between the legs with the fluoroscopic monitor at the foot. (From ref. 13, with permission.)

Fig. 8 Byrd 2001 ‘Advanced Arthroscopy’ ISBN 0-387-98808-4 Springer-Verlag Image:Figure 27.10 and 27.12

ensure safety and improve visualisation [27]. Byrd and his colleagues describe techniques and optimum portal placement to minimise damage to extra-articular structures [28], and he has continued to publish numerous textbooks and papers on the subject up until the present. On portal placement, Byrd explained that efficient and safe portal placement relies on the accurate marking of anatomic landmarks. He described this land-marking: the superficial and palpable landmarks of the greater trochanter and the anterior superior iliac spine, and the deeper bony landmarks viewed fluoroscopically of the femoral neck and head. Careful land-marking should ensure that portal placement for hip arthroscopy is entirely safe.

Joe McCarthy in the United States became and has also remained active as a 'prolific author and educator', as described by Byrd [29]. He advocates hip arthroscopy for treating patients who have reproducible symptoms and are limited in function, to investigate unexplained symptoms after hip replacement and in some trauma settings [30]. He also foresees many opportunities, including perhaps biologic joint reconstruction via arthroscopy [31].

Although hip arthroscopy, particularly in America, has focused on techniques with distraction, there has been work on hip arthroscopy without distraction as Henri Dorfmann and Thierry Boyer in France described well in their retrospective report of 1999 [32]. They point out that most hip abnormalities are to be found in the peripheral compartment and therefore can be well visualised without distraction, and also hold that distraction has the disadvantage of tightening the hip capsule so that the capsule moves closer to the bone. Dienst et al carried on some work without distraction in the US, and also advocate that it is preferable in certain cases, even if it does not allow adequate visualisation of the central compartment [33].
Dienst's successful integration of arthroscopy of the intraarticular joint with that of the periphery was to be key in the development of arthroscopic access of femoroacetabular impingement (FAI) lesions, pioneered by Professor Reinhold Ganz and his colleagues in Bern, Switzerland [34].

\section{Current status and future directions}

The steady stream of recent peer-reviewed scientific publications in both the basic science and clinical applications of hip arthroscopy are beyond the scope of this brief overview. Perhaps the founding of the ISHA by Richard Villar in 2008 [35] (Fig. 9), and its popular annual meetings since then is the best indicator of the recent surge of innovation and evidencebased medicine in this exciting field. This society has championed hip arthroscopy as an evolving area, encouraged company support for instrument development, and supported worldwide training courses.Hip arthroscopy today enjoys excellent visualisation (Fig. 10). The indications for hip arthroscopy have developed alongside its role as a diagnostic tool: pathologies have emerged which were difficult to diagnose either clinically or using traditional radiology. Diagnostically, hip arthroscopy, therefore, has an exploratory role in the treatment of undiagnosed hip or groin pain. It may also be used to investigate a hip effusion or synovitis. Therapeutically, there are now many indications for hip arthroscopy, including the removal of loose bodies, resection of a torn ligamentum teres, snapping hip, trochanteric bursitis and gluteus medius tears [36, 37]. The most common therapeutic intervention is in the treatment of FAI and labral tears. 


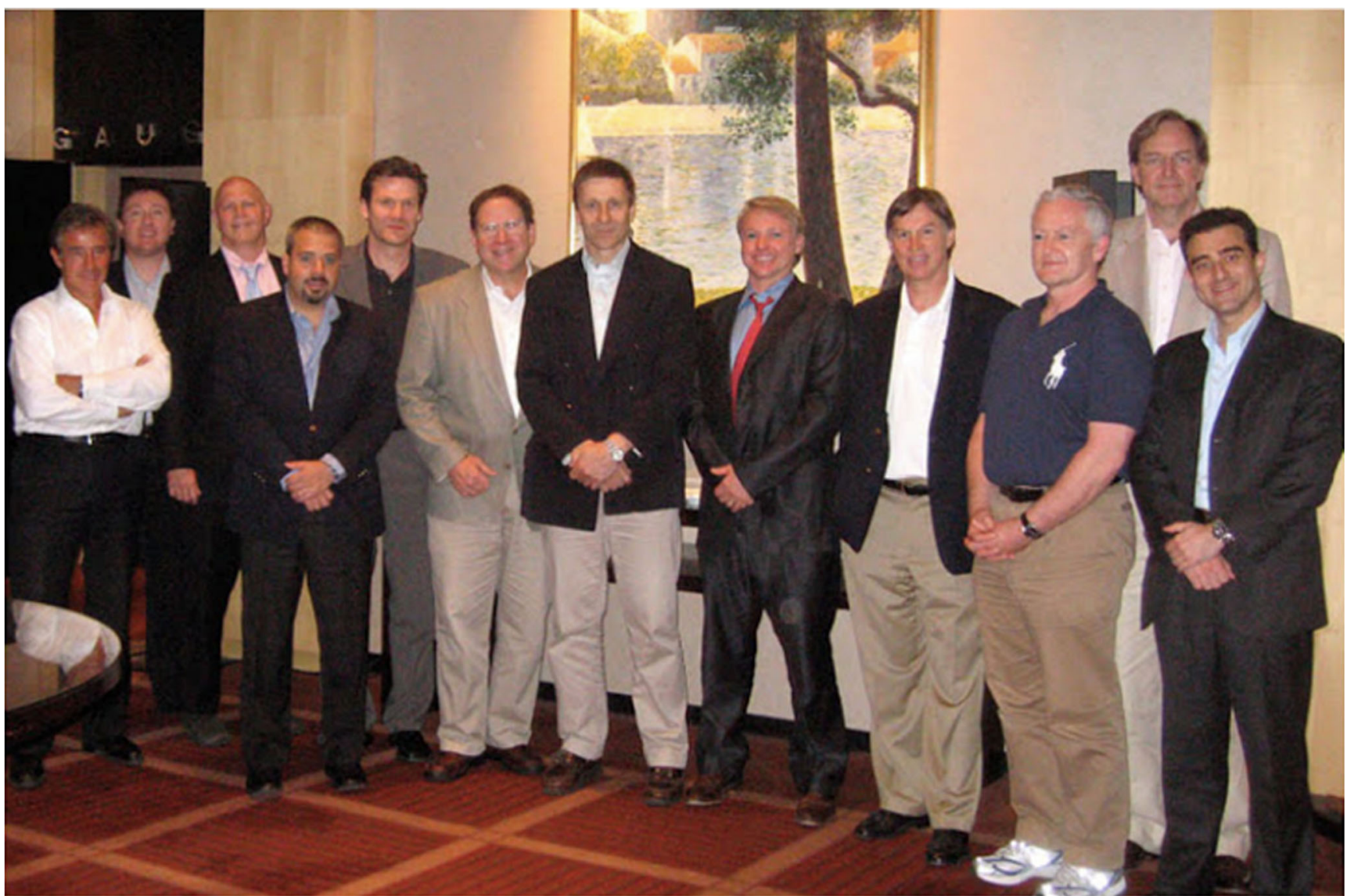

Fig. 9 Byrd 2013 (see above)

FAI is a young pathology, first described by Myers, Eijer and Ganz in 1999 [38]. It is defined as the abutment between the proximal femur and the acetabular rim [39]. It is a common cause of hip pain in young adults, diagnosed via CT and MRI scans. Two different mechanisms are described, although a combination of both is seen in clinical practice. Cam lesions are due to reduced anterior femoral head-neck offset. Pincer lesions are from abnormalities on the acetabular side. FAI due to either mechanism can lead to labral pathology and chondral lesions. Also, the abnormal kinematic and kinetic patterns associated with FAI have been discussed recently, highlighting similarities between the gait seen in early osteoarthritis and that
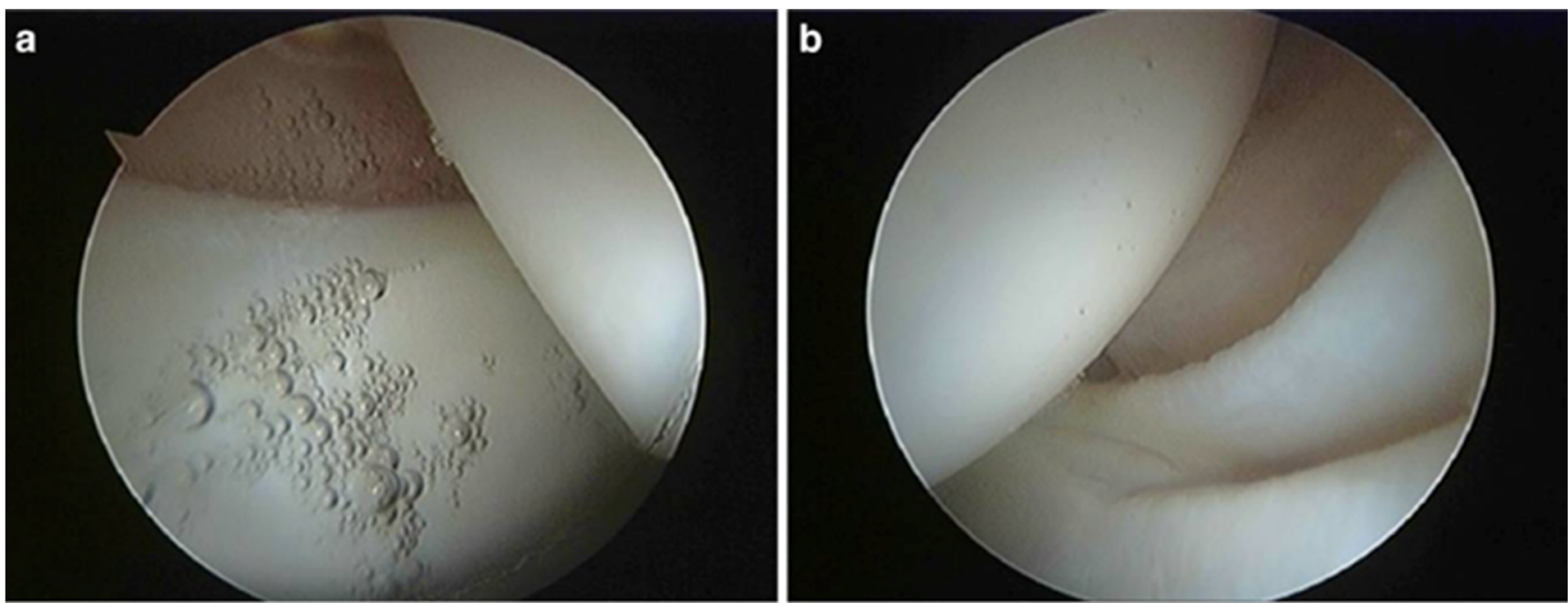

Fig. 10 Khanduja and Griffiths, 2012 'Hip arthroscopy: evolution, current practice and future developments' in International Orthopedics 36(6):11151121 
of FAI [40]. Surgery is the treatment of choice, and whilst more evidence is needed to assess the comparison of open surgery versus hip arthroscopy [41], the arthroscopic approach certainly offers a minimally invasive, safe route to a definitive treatment. In general, a recent meta-analysis of 81 studies of primary hip arthroscopy suggests that it seems to offer good outcomes with respect to patient acceptable symptomatic state and minimal clinically important difference [42].

As techniques improve, hip arthroscopy becomes more widespread [43], and the international community of evidence-based surgeons performing it grows, there is promise for a future of diagnosing and treating ever more conditions with ever-lower rates of complications. Mark Philippon in Vail has described successful repair of the labrum [44]. This last development is particularly exciting in that it represents the transition of hip arthroscopy from resection to restorative reconstructive techniques. A significant transition that swells the indications for hip arthroscopy to include many more pathologies. Computer-aided techniques have already been described and may, in the future, enable more targeted interventions with an associated improvement in outcomes [45]. This has the potential to allow arthroscopy to slow or halt the progression of the degenerative joint disease. Technological advances are hard to predict in this fast-moving age, but 3D arthroscopy and virtual reality arthroscopy training are currently in development [2].

\section{Conclusion}

As previously discussed in this journal, history can be a valuable tool in orthopaedic education [46]. Certainly, the authors feel that their understanding and appreciation of hip arthroscopy has been deepened by this foray into its history. Hip arthroscopy is still a specialised operative technique, not offered in all centres, but is becoming more and more widely available. It is a valuable and still-evolving area of surgery, with numerous applications, both diagnostic and therapeutic. This young orthopaedic surgery has a promising future.

\section{Compliance with ethical standards}

Conflict of interest The authors declare that they have no conflict of interest.

Funding There is no funding source.

Ethical approval This article does not contain any studies with human participants or animals performed by any of the authors.

Open Access This article is distributed under the terms of the Creative Commons Attribution 4.0 International License (http:// creativecommons.org/licenses/by/4.0/), which permits unrestricted use, distribution, and reproduction in any medium, provided you give appropriate credit to the original author(s) and the source, provide a link to the Creative Commons license, and indicate if changes were made.

\section{References}

1. Jackson R, Keiser C (2000) Arthroscopy: minimally invasive surgery changed the face of orthopedics. Orthopedics today, Healio, http://www.healio.com/orthopedics/arthroscopy/news/online/\% 7B4d8cd800-f1ae-44ea-bd48-022652b184e8\% 7D/arthroscopyminimally-invasive-surgery-changed-the-face-of-orthopedics. Accessed 7 September 2016

2. Passler H, Yang Y (2012) The past and the future of arthroscopy. In: Doral et al (ed) Sports injuries: prevention, diagnosis, treatment and rehabilitation. Springer, Berlin, pp 5-13

3. Nordentoft S (1912) Ueber Endoskopie geschlossener Cavitäten mittels meines Trokart-Endoskopes. Verh Dtsch Ges Chi, 78-81

4. Kieser CW, Jackson CR (2001) Severin Nordentoft: the first arthroscopist. Arthroscopy 5(17):532-535

5. Takagi K (1939) The arthroscope: the second report. J Jpn Orthop Assoc 14:441-466

6. Bircher E (1921) Die Arthroendoskopie. Zentralbl Chir 48:1460 1461

7. Bircher E (1933) Ueber Binnenverletzungen des Kniegelenks. Arch Klin Chir 199:290-359

8. Burman M (1931) Arthroscopy or the direct visualization of joints. J Bone Jt Surg 13(4):669-694

9. Watanabe M, Takeda S, Ikeuchi H (1979) Atlas of arthroscopy, 3rd edn. Igaku-Shoin, Tokyo

10. Aignan M (1976) Arthroscopy of the hip. Rev Int Rheumatol 33

11. Gross RH (1977) Arthroscopy in hip disorders in children. Orthop Rev 6:43-49

12. Holgersson S, Brattström H, Mogensen B, Lidgren L (1981) Arthroscopy of the hip in juvenile chronic arthritis. J Pediatr Orthop 1(3)

13. Vakili F, Salvati E, Warren R (1980) Entrapped foreign body within the acetabular cup in total hip replacement. Clin Orthop Relat Res 150:159-162

14. Shifrin L, Reis N (1980) Arthroscopy of a dislocated hip replacement: a case report. Clin Orthop Relat Res 146:213-214

15. Eriksson E, Arvidsson I, Arvidsson H (1986) Diagnostic and operative arthroscopy of the hip. Orthopedics 9(2):169-176

16. Kandil A, Safran MR (2016) Hip arthroscopy: a brief history. Hip Arthrosc 35(3):321-329

17. Glick JM, Sampson TG, Gordon RB, Behr JT, Schmidt E (1987) Hip arthroscopy by the lateral approach. Arthroscopy 3(1):4-12

18. Gelijns A, Rosenberg N (1995) From the Scalpel to the scope: endoscopic innovations in gastroenterology, gynecology, and surgery. In: Dawkins H, Gelijns A, Rosenberg N (eds) Sources of medical technology: universities and industry. National Academies Press (US), Washington (DC), https://www.ncbi.nlm. nih.gov/books/NBK232053. Accessed 15 September 2016

19. Baird J (1937) British patent specifications. Patent number 20, 969/27

20. Hopkins H, Kapany N (1954) A flexible fibrescope, using static scanning. Nature 173:39-41

21. van Heel AC (1954) A new method of transporting optical images without aberrations. Nature 173:39

22. Hirschowitz B (1979) A personal history of the fiberscope. Gastroenterology 76(4):864-869

23. Williams NS Bailey and Love's short practice of surgery, 25th edn. Hodder Arnold, London

24. Hawkins RB (1989) Arthroscopy of the hip. Clin Orthop Relat Res 249(44-47) 
25. Villar RN (1992) Hip arthroscopy. Butterworth-Heinemann, Oxford

26. Shetty VD, Villar RN (2007) Hip arthroscopy: current concepts and review of literature. Br J Sports Med 41(2):64-68

27. Byrd JWT (1994) Hip arthroscopy utilizing the supine position. Arthrosc J Arthrosc Relat Surg 10(3):275-280

28. Byrd JWT, Pappas JN, Pedley MJ (1995) Hip arthroscopy: an anatomic study of portal placement and relationship to the extraarticular structures. Arthrosc J Arthrosc Relat Surg 11(4):418-423

29. Byrd JWT (2013) Overview and history of hip arthroscopy. In: Byrd (ed) Operative hip arthroscopy, 3rd edn. Springer, New York, pp 1-6

30. McCarthy JC (2004) Hip arthroscopy: when it is and when it is not indicated. Instr Course Lect 53:615-621

31. McCarthy JC, Lee JA (2011) History of hip arthroscopy: challenges and opportunities. Clin Sports Med 30(2):217-224

32. Dorfmann H, Boyer T (1999) Arthroscopy of the hip: 12 years of experience. Arthroscopy 15(1):67-72

33. Dienst M, Gödde S, Seil R, Hammer D, Kohn D (2001) Hip arthroscopy without traction. Arthroscopy 17(9):924-931

34. Leunig M, Mast NH, Impellizerri FM, Ganz R, Panaro C (2012) Arthroscopic appearance and treatment of impingement cysts at femoral head-neck junction. Arthroscopy 28(1):66-73

35. ISHA (2016) About ISHA. The International Society for Hip Arthroscopy. http://www.isha.net/isha.html. Accessed 9 September 2016

36. Griffiths EJ, Khanduja V (2012) Hip arthroscopy: evolution, current practice and future developments. Int Orthop 36(6):1115-1121
37. Bardakos NV, Villar RN (2008) The ligamentum teres of the adult hip. J Bone Amp Jt Surg Br 91-B(1):8

38. Myers S, Eijer H, Ganz R (1999) Anterior femoroacetabular impingement after periacetabular osteotomy. Clin Orthop Relat Res 363(93-99)

39. Ganz R, Parvizi J, Beck M, Leunig M, Notzli H, Siebenrock K (2003) Femoroacetabular impingement: a cause for osteoarthritis of the hip. Clin Orthop Relat Res 417:112-120

40. Alshameeri Z, Khanduja V (2014) The effect of femoro-acetabular impingement on the kinematics and kinetics of the hip joint. Int Orthop 38(8):1615-1620

41. Banerjee P, Mclean CR (2011) Femoroacetabular impingement: a review of diagnosis and management. Curr Rev Musculoskelet Med 4(1):23-32

42. Levy DM, Kuhns BD, Chahal J, Philippon MJ, Kelly BT, Nho JT (2016) Hip arthroscopy outcomes with respect to patient acceptable symptomatic state and minimal clinically important difference. Arthroscopy 32(9): 1877-1886

43. Imam S, Khanduja V (2011) Current concepts in the diagnosis and management of femoroacetabular impingement. Int Orthop 35(10): $1427-1435$

44. Philippon MJ, Faucet SC, Briggs KK (2013) Arthroscopic hip labral repair. Arthrosc Tech 2(2):e73-e76

45. Nakano N, Krekel P, Pattyn C, Audenaert E (2017) Accuracy of navigated cam resection in femoroacetabular impingement. a randomised controlled trial. Int J Med Robot, In press

46. Hernigou P, Pecina M (2013) History as a tool in Orthopedic education. Int Orthop 37(3):351-353 